\title{
Findings Associated with Pulmonary Hypertension: CT Angiography Based Study
}

\author{
Salah Eldein Hassan Aloub, Caroline Edward Ayad, \\ Mohammed Elfadil Mohammed Gar Elnabi \\ College of Medical Radiological Science, Sudan University of Science and Technology, Khartoum, Sudan \\ Email: carolineayad@yahoo.com
}

Received 26 June 2016; accepted 2 August 2016; published 5 August 2016

Copyright (C) 2016 by authors and Scientific Research Publishing Inc.

This work is licensed under the Creative Commons Attribution International License (CC BY). http://creativecommons.org/licenses/by/4.0/

(c) (i) Open Access

\begin{abstract}
Pulmonary hypertension (PH) is a complex disorder and may be related to a variety of diseases. It may arise in association with chronic thromboembolic pulmonary hypertension (CTEPH) or pulmonary embolism (PE). Knowledge of the radiological features is required to characterize and accurately diagnose the conditions and may improve the outcome. This study was designed to evaluate the clinical characteristics and the computerized tomography angiography findings in patients with PH, PE and CTEPH. Contrast-enhanced CT scans were acquired in 55 Sudanese patients with PE, 20 patients with $\mathrm{PH}, 25$ patients with CTEPH and 50 normal subjects who were considered as control group. The CT diagnostic criteria for all cases were characterized. The clinical signs, parenchymal abnormalities, pulmonary tree and cardiac segments in all groups were characterized and compared with the control group. The results showed that the most common clinical characteristics were found to be chest pain, dyspnea, lower limb swelling, tachycardia and syncope which were correlated significantly with the presence of the disease. In all patients groups, the pulmonary vascular segments, cardiac segments and lung parenchyma changes were detected and were significantly different from the normal control subjects at $\mathbf{p} \leq \mathbf{0 . 0 1}$. It was found that $\mathrm{CT}$ angiography has a significant role in the diagnostic evaluation of these groups of patients. CT imaging is acceptably used in diagnosis, defining cause, quantifying heart segments and parenchyma changes in order to assess the feasibility of surgery, monitoring and therapeutic planning.
\end{abstract}

\section{Keywords}

Pulmonary Hypertension (PH), Pulmonary Artery Diameter, Computed Tomography (CT), Pulmonary Embolism

\section{Introduction}

Pulmonary hypertension (PH) is a complex disorder [1]. Definition of PH is based on shared pathophysiology 
that categorizes many classes of PH: pulmonary arterial hypertension (PAH), which may be idiopathic (IPAH) or associated with left heart disease; or lung disease in association with chronic thromboembolic pulmonary hypertension (CTEPH) [2]. In patients with PAH, progressive narrowing of the small pulmonary arteries and arterioles results in increased pulmonary vascular resistance, which may ultimately lead to right ventricular failure. Vasoconstriction and thrombosis in situ are factors rising vascular resistance [3].

According to the diagnostic approach to PH that was proposed in 1997 by Reaside and Peacock [4], the ability to differentiate CTEPH and primary PH relies on computed tomography (CT), which enables recognition of chronically obstructed vessels [5]-[11]. The occurrence of CTEPH in the general population may have been significantly underestimated. Recent epidemiologic records specify an incidence of $4 \%$ after acute symptomatic pulmonary embolism (PE) [12] [13]. The growing number of patients undergoing chest CT who might have PE is an increasingly common finding on chest CT images [14]. Symptoms are non-specific and are related to the progress of $\mathrm{PH}$. The vascular obstruction is a most important character of $\mathrm{PH}$. In the majority of symptomatic patients, more than $40 \%$ of the pulmonary vascular bed is obstructed [15] [16]. Patients with CTEPH are asymptomatic before their presentation with symptoms [15]-[18]. The clinical worsening corresponds to the loss of right ventricular functional capability. In these patients, pulmonary arterial pressure is elevated and right atria pressures are high [16].

Therefore early and appropriate diagnosis and treatment are required; in this study, we evaluated the clinical characteristics, the CT findings in PH, PE and CTEPH patients. We have expressed the technique for CT angiography and the CT diagnostic criteria for all cases and correlated the findings with normal control. Knowledge of the radiological signs is required to detect and accurately diagnose the condition and may improve the outcome. In the current study the pulmonary artery tree, heart segments and associated lung parenchyma findings have been evaluated and the added value of CT in prediction of estimating PH comparing with the normal control group was analyzed.

\section{Materials and Methods}

\subsection{Area and Duration of the Study}

This study is a descriptive analytical study, it was done at Royal Care International Hospital and Doctor's Clinic Radiology Departments; Data were collected during the period from October 2013 to December 2015.

\subsection{Study Population}

A sample of 55 patients with clinically diagnosed as PE was enrolled, their mean ages were $54.20 \pm 14.21$ ranged from 28 - 95 years old and a sample of 20 patients with PH, mean ages were $60.4 \pm 13.96$ ranged from 29 - 75 years and 25 patients with CTEPH were enrolled, their mean ages were $61.24 \pm 9.5$ ranged from 47 - 85 years old. 50 normal subjects were considered as control, their mean ages was $50.7 \pm 14.5$ ranged from 21 - 76 years old. The sample included both genders; the total number of females were $92(61.3 \%)$, female patients who were affected with $\mathrm{PE}=37$ (67.3\%), $\mathrm{PH}=10(50.0 \%)$ and CTEPH $=11$ (44.0\%), the normal control constituting 34 (68.0\%). Total number of male patients were 58 (38.7\%) and who were affected with $\mathrm{PE}=18(32.7 \%), \mathrm{PH}=$ $10(50.0 \%)$ and CTEPH $=14$ (56.0\%) and the normal male controls constituting 16 (32.0\%).

All were examined by using CT. Those were referred to CT examination were with clinical presentation including shortness of breath, chest pain, swallowing in legs. The selection criteria for PE and PH were those who were diagnosis were based on clinical findings. The normal control group was those who were scanned for CT angiography and their findings are without cardiac, pulmonary or lung parenchyma disorders. For the selection criteria of the CTEPH patients; the diagnosis is made principally through CT imaging findings and clinical setting. We considered the key feature of CTEPH is that: in the CTPA findings of CTEPH; the presence of thrombosis, occlusion, and post stenotic dilatation in the pulmonary arteries, changing of lung pattern, presence of collaterals and puluroparenchemal changes are considered the CT findings in CTEPH.

Exclusion criteria were non availability of medical records, or have contraindication of intravenous iodinated contrast. Verbal consent was firstly obtained from all potential participants. The aims, benefits of the present study were explained to all participants in details. Medical, history of all study subjects posing as (sample) were thoroughly reviewed directly from participants themselves and those with conditions that may in any way, alter the findings of the current study were excluded. 


\subsection{Instrumentation and Technique}

Toshiba (64 multi-slice detector) in Royal Care International Hospital and Neo soft (64 multi-slice detector) in Doctor's Clinic.

CTA was obtained during spiral data acquisition, the entire area of interest was scanned during the injection of contrast. Images were captured when vessels are fully opacified to demonstrate either arterial or venous phase enhancement through the acquisition of both data sets (arterial and venous). A ROI (region of interest) is positioned over the pulmonary artery at the level of the carina. After commencing the injection a (tracker scan) Hounsfield level at the ROI was monitored and the scan is the triggered when the density at the ROI reaches a preset value. Detector width-reconstruction/(mm) $=0.625-1.25$. Scan direction and extension-caudal-cranial direction scan from hemi diaphragm to the lung apex. Imaging review and post-processing, imaging should be reviewed at three setting: Mediastinal window (window width-window level (400 - $40 \mathrm{HU}$ ), Pulmonary embolism-specific window (700 - $1000 \mathrm{HU})$, Lung window (1500 - $600 \mathrm{HU})$. Patients were instructed on breath-holding techniques. Collimation $(1-2 \mathrm{~mm})$, Table speed $(2-4 \mathrm{~mm} / \mathrm{sec})$, Gantry rotation time $(\mathrm{ms})=330-420$ $\mathrm{mm} / \mathrm{sec}$, Tube voltage $/(\mathrm{KV})=120 \mathrm{kv}$, Tube current time product $/(\mathrm{mAs})=125 \mathrm{mAs}$, Normal pitch/(mm) $=0.9$, Reconstruction slice thickness $/(\mathrm{mm})=0.6$. CT angiography contrast parameters for pulmonary artery: Concentration $(\mathrm{mg}$ iodine $/ \mathrm{ml})=350-400$, Injection Rate $(\mathrm{ml} / \mathrm{s})=3 \mathrm{ml} / \mathrm{sec}$, Volume $/(\mathrm{ml})=60-120 \mathrm{ml}$, Delay $(\mathrm{s})=12$ sec Saline chaser $(\mathrm{ml}, \mathrm{ml} / \mathrm{s})=30$, 3.0.

\subsection{Image Analysis}

1) Pulmonary artery: The widest short axis diameter of the main pulmonary artery at the level of carina and the transverse diameter of the right and left main pulmonary branches as well as the distal portions on the same image slice were measured.

2) Right ventricle: The right ventricular cavity was measured in the axial plane at their widest points between the inner surfaces of the free wall and the interventricular septum; where the interventricular septal configuration was measured in (mm).

4) Right atrial: The right atrial diameter was measured on the axial mid-chamber view that showed the centre of tricuspid annulus and the superior right atrial wall.

\section{Results and Discussion}

Evaluation of patients with suspected pulmonary hypertension requires proper investigations to confirm the diagnosis, clarify and determine the specific cause. Thus, evaluating patients with pulmonary hypertension involves four steps: suspicion, detection, classification and functional evaluation [19]. Suspicion including symptoms and conditions which are associated with a risk for developing pulmonary hypertension. Early detection of pulmonary hypertension is vital for appropriate treatment [20]-[22]. Classification with a systematic approach to determine its cause to rule out the more common clinical groups of pulmonary hypertension such as left-sided heart disease, lung disease, and chronic thromboembolic pulmonary hypertension (CTEPH). CTEPH is often has been misdiagnosed because patients present with nonspecific symptoms. Knowledge of the radiologic imaging signs is required to detect and accurately diagnose the condition. Because CTEPH is potentially curable with pulmonary thromboendarterectomy, early recognition may improve the outcome [23] therefore our study was obtained to characterize patients with PE, PH and its complications. Thus the following tables presented the results of the characterization of the cardiac segments, pulmonary changes in PH, PE and CTEPH.

Our sample demonstrate that the patients affected with $\mathrm{PH}$ after affected with PE were 25 patient with the most affected ages were between 51 - 60 years constituting 11 (44.0\%), where those who were affected with PE only were 18 (32.7\%) for the same age group however the PH percentage were distributed in all group of ages between 21 years and ages $>71$ years old. This was presented in Table 1 .

Classification of patients according to their complaints has been studied as seen in Table 2. Studies have mentioned that patients with CTEPH may be asymptomatic for several years before their presentation with symptoms such as dyspnea, atypical chest pain, tachycardia and syncope. The clinical deterioration parallels the loss of right ventricular functional capacity [15]-[18]. Our study evaluated all of the clinical and radiological findings in patients with PH, PE and CTEPH.

The main clinical finding was chest pain. In PE patients; leg swelling was found in only 2 (3.6\%) of the cases, it is important to acknowledge a history of deep vein thrombosis (sign: as lower limb swelling) as an element that 
can guide the diagnosis, but it lacks sensitivity. Previous studies had mentioned that many patients with CTEPH haven't had a documented DVT [24] [25]. Patients monitored for pulmonary hypertension of another cause may exhibit symptoms similar to those of CTEPH [26] this was similar to the findings of our study. Tachycardia and Syncope were also present with least frequencies.

The classic multidetector computed tomography pulmonary angiography (CTPA) findings of pulmonary hypertension were divided into three categories: vascular, cardiac, and parenchymal [27]. Table 3 presented classification of the sample according to the associated findings in the pluroparenchema and heart, and were presented in frequency and percentages and were cross tabulated with the type of disease. The current study mentioned that several pulmonary parenchymal findings are associated with $\mathrm{PH}$, these findings include mosaic attenuation which is commonly seen in chronic pulmonary thromboembolic disease constituting 7 (28.0\%), but also seen in

Table 1. Classification of the sample (patients with PE, PH, CTEPH) according to age class, frequency and percentages, age intervals of 10 years.

\begin{tabular}{|c|c|c|c|c|c|}
\hline & \multicolumn{4}{|c|}{ Type of Disease } & \multirow{2}{*}{ Total } \\
\hline & Patients with $\mathrm{PE}^{*} \mathrm{~N}=55$ & Patients with $\mathrm{PH}^{* *} \mathrm{~N}=20$ & Patients with CTEPH ${ }^{* * *} \mathrm{~N}=25$ & Normal Subjects $N=50$ & \\
\hline $21-30$ & $3(5.5 \%)$ & $1(5.0 \%)$ & $0(0.0 \%)$ & $5(10.0 \%)$ & $9(6.0 \%)$ \\
\hline $31-40$ & $7(12.7 \%)$ & $3(15.0 \%)$ & $0(0.0 \%)$ & $12(24.0 \%)$ & $22(14.7 \%)$ \\
\hline $41-50$ & $11(20.0 \%)$ & $0(0.0 \%)$ & $4(16.0 \%)$ & $10(20.0 \%)$ & $25(16.7 \%)$ \\
\hline $51-60$ & $18(32.7 \%)$ & $4(20.0 \%)$ & $11(44.0 \%)$ & $8(16.0 \%)$ & $41(27.3 \%)$ \\
\hline $61-70$ & $11(20.0 \%)$ & $7(35.0 \%)$ & $6(24.0 \%)$ & $12(24.0 \%)$ & $36(24.0 \%)$ \\
\hline$>71$ & $5(9.1 \%)$ & $5(25.0 \%)$ & $4(16.0 \%)$ & $3(6.0 \%)$ & $17(11.3 \%)$ \\
\hline
\end{tabular}

"pulmonary embolism (PE), ${ }^{* *}$ pulmonary hypertension (PH), ${ }^{* * *}$ chronic thromboembolic pulmonary hypertension (CTEPH).

Table 2. Frequency (expressed in percentage) of patients complains in patients PE, PH, CTEPH.

\begin{tabular}{cccc}
\hline \multirow{2}{*}{ Patient Complain } & \multicolumn{3}{c}{ Type of Disease } \\
\cline { 2 - 4 } & Patients with PE N = 55 & Patients with PH N = 20 & Patients with CTEPH N = 25 \\
\hline Chest Pain & $38(69.1 \%)$ & $19(95.0 \%)$ & $18(75.0 \%)$ \\
Short of Breathing & $33(60.0 \%)$ & $16(80.0 \%)$ & $22(88.0 \%)$ \\
Leg Swelling & $2(3.6 \%)$ & $0(0.0 \%)$ & $2(0.0 \%)$ \\
Tachycardia & $1(1.8 \%)$ & $0(0.0 \%)$ & $0(0.0 \%)$ \\
Syncope & $1(1.8 \%)$ & $0(0.0 \%)$ & $0.0 \%)$ \\
\hline
\end{tabular}

Table 3. Frequency (expressed in percentage) of the CT finding in patients with PE, PH, CTEPH.

\begin{tabular}{cccc}
\hline \multirow{2}{*}{ CT Findings } & \multicolumn{3}{c}{ Type of Disease } \\
\cline { 2 - 4 } & Patients with PE (N = 55) & Patients with PH (N = 20) & Patients with CTEPH (N = 25) \\
\hline Pleural Effusion & $21(38.2 \%)$ & $2(10.0 \%)$ & $3(12.0 \%)$ \\
Consolidation & $25(45.5 \%)$ & $6(30.0 \%)$ & $14(56.0 \%)$ \\
Ground Glass Opacity & $3(5.5 \%)$ & $3(15.0 \%)$ & $3(12.0 \%)$ \\
Mosaic Appearance & $5(9.1 \%)$ & $2(10.0 \%)$ & $9(36.0 \%)$ \\
Abnormal Right Ventricle Morphology & $11(20.0 \%)$ & $6(30.0 \%)$ & $6(24.0 \%)$ \\
\hline
\end{tabular}


cases with PH, 2 (10.0\%). Similar findings were mentioned by another similar study done by Eduardo Jose et al., 2012 [28].

In order to diagnose the CTEPH, CTPA features should be identified. We classify the features of chronic pulmonary thromboembolism as vascular signs or parenchymal signs. The vascular signs include direct pulmonary artery signs and signs due to pulmonary hypertension. The parenchymal signs include mosaic perfusion pattern, focal ground glass opacities. This method and findings was similar to the study done by Eva Castañer, et al. (2009) [14]. Pleural Effusion was seen with the highest score of percentage constituting 21 (38.2\%) in PE cases.

Ground glass opacity was also been detected as a complication of PH in CTEPH. Similar previous studies have mentioned that the parenchymal signs as centrilobular ground-glass nodules are common in patients with pulmonary hypertension [29] however nodules are also seen in patients with other pulmonary capillary diseases [30] [31]. The occurrence of that appearance in our cases; is that the systemic perfusion of the peripheral pulmonary arterial bed accounts for the presence of isolated focal areas, this area was described in previous studies as ground-glass attenuation [6] [32]. Arakawa et al. [33] found direct evidence of airway obstruction-air trapping in patients with chronic pulmonary thromboembolism. Air trapping is commonly seen in areas of hypo perfusion due to chronic embolism. This is what our study perceived is that the most of the patients came with shortness in breathing in both PE and CTEPH as seen in Table 2.

Consolidation scored the high frequency in both CTEPH and PE, cardiomegally constituting 6/25 (24.0\%) of the CTEPH cases. The current study showed that 30\% of patients with (PH) and 36\% with (CTEPH) have abnormal right ventricle morphology and supposed that the hypertrophied right ventricle made it spherical shape and greater than the left ventricle. The justification of this fact is that the demand of the right ventricle for oxygen exceeds the available supply, causing chamber dilation that leads to tricuspid regurgitation, a result of tricuspid annular dilatation and incomplete valve closure, these processes eventually result in right-sided heart morphology changes, this process is described well is other related studies [23] [34] [35]. This was presented in Table 3.

Pulmonary trunk diameter in PH patients and CTEPH was found to be larger than patients with (PE) and normal control. The maximum width were found to be $55 \mathrm{~mm}$ and $42 \mathrm{~mm}$ which were consistent with the diagnostic criteria of pulmonary hypertension, that was mentioned previously that the enlargement of the main pulmonary artery to a diameter of more than $29 \mathrm{~mm}$ occurs in the presence of pulmonary hypertension [18] regardless of the cause; such enlargement is a common finding in patients with chronic thromboembolic pulmonary hypertension [36]. The study also presented that the least effect on the main trunk diameter was found in cases of PE (Table 4). The diameter of the main pulmonary artery is measured in the scanning plane of its bifurcation, at a right angle to its long axis, followed by measurements done for right and left main pulmonary arteries diameter. The normal value of main pulmonary trunk diameter was found to be $25.17 \pm 3.33$ mm measured for 50 normal Sudanese subjects. Several published studies provide different normative data. Edwards et al. reported that the mean pulmonary artery dimension was $27.2 \mathrm{~mm}$ (SD 0.6) in 100 Caucasian participants [37]. Karazincir et al. reported a mean diameter of the main pulmonary artery of $26.6 \mathrm{~mm}$ (SD 2.9) in 112 patients [38]. Kuriyama et al. reported a somewhat smaller mean pulmonary artery size of $24.2 \mathrm{~mm}$ (SD 2.2) in sample of Japanese origin [39]. The possible discrepancy may be due to the differences in race or CT technique [40]. It is important to emphasize that a diameter of less than $29 \mathrm{~mm}$ does not necessarily exclude pulmonary hypertension. In patients with mild pulmonary hypertension, the pulmonary artery may be only slightly dilated, and the findings in patients with (PH) may overlap with those in control subjects without PH [37] [41]. The diameters of the segmental pulmonary arteries should also been dilated in the presence of pulmonary hypertension [27].

The maximum changes in diameter differs from the normal by $1.81 \mathrm{~mm}, 4.13 \mathrm{~mm}, 5.2 \mathrm{~mm}$ for the right main pulmonary artery diameter and $1.49 \mathrm{~mm}, 4.26$, $4.56 \mathrm{~mm}$ left main pulmonary artery diameter in PE, PH and CTEPH respectively with the maximum changes detected in the PH cases (Table 4), also changes were detected in both right and left distal pulmonary artery diameter with greater changes detected in PH and CTEPH. Another similar study has also mentioned that pulmonary enlargement typically seen in pulmonary hypertension and chronic thromboembolic pulmonary hypertension [42].

Cardiac signs in $\mathrm{PH}$ are the adaptation and failure of the right side of the heart that may be seen as right ventricular hypertrophy, straightening or leftward bowing of the interventricular septum; right ventricular dilatation and other findings [43]-[46]. Therefore the heart segments of all of the study sample were also been evaluated including right atrium diameter, right ventricle diameter, interventriculer width, and myocardium thickening in all 
Table 4. Mean and standard deviation of the measured variables (heart segments and pulmonary tree) in all the patients and normal.

\begin{tabular}{|c|c|c|c|c|c|}
\hline Variables & Cases & $\mathrm{N}$ & Mean $(\mathrm{mm}) \pm$ Std. Deviation & Minimum (mm) & Maximum (mm) \\
\hline \multirow{4}{*}{ Right Atrium Diameter (mm) } & $\mathrm{PE}$ & 55 & $49.51 \pm 8.54$ & 33.20 & 87.30 \\
\hline & PH & 20 & $60.31 \pm 11.49$ & 37.50 & 90.70 \\
\hline & СТЕРН & 25 & $57.42 \pm 9.19$ & 41.70 & 84.70 \\
\hline & Normal & 50 & $46.43 \pm 6.44$ & 36.70 & 77.00 \\
\hline \multirow{4}{*}{ Right Ventricle Diameter (mm) } & $\mathrm{PE}$ & 55 & $46.03 \pm 6.23$ & 32.90 & 68.30 \\
\hline & PH & 20 & $51.41 \pm 6.34$ & 41.30 & 64.60 \\
\hline & СТЕРН & 25 & $51.31 \pm 5.94$ & 36.50 & 58.70 \\
\hline & Normal & 50 & $42.25 \pm 3.85$ & 35.60 & 53.70 \\
\hline \multirow{4}{*}{ Inter-Ventricular Septum Width (mm) } & $\mathrm{PE}$ & 55 & $11.38 \pm 1.82$ & 8.30 & 20.80 \\
\hline & $\mathrm{PH}$ & 20 & $10.81 \pm 2.14$ & 6.00 & 12.90 \\
\hline & СТЕРН & 25 & $12.16 \pm 1.98$ & 5.70 & 15.30 \\
\hline & Normal & 50 & $11.00 \pm 1.13$ & 8.30 & 13.00 \\
\hline \multirow{4}{*}{ Myocardium Thickening } & $\mathrm{PE}$ & 55 & $7.1636 \pm 0.97$ & 5.50 & 10.50 \\
\hline & $\mathrm{PH}$ & 20 & $6.95 \pm 0.66$ & 6.20 & 9.20 \\
\hline & СТЕРН & 25 & $7.37 \pm 0.88$ & 6.10 & 9.10 \\
\hline & Normal & 50 & $6.95 \pm 0.77$ & 5.30 & 9.60 \\
\hline \multirow{4}{*}{ Pulmonary Trunk Diameter (mm) } & $\mathrm{PE}$ & 55 & $28.00 \pm 3.70$ & 19.50 & 37.10 \\
\hline & $\mathrm{PH}$ & 20 & $34.54 \pm 6.97$ & 26.00 & 55.00 \\
\hline & СТЕРН & 25 & $33.86 \pm 3.63$ & 27.20 & 42.30 \\
\hline & Normal & 50 & $25.17 \pm 3.33$ & 19.00 & 34.30 \\
\hline \multirow{4}{*}{ Right Main Pulmonary Artery Diameter (mm) } & $\mathrm{PE}$ & 55 & $20.70 \pm 3.33$ & 15.40 & 29.70 \\
\hline & $\mathrm{PH}$ & 20 & $23.02 \pm 3.63$ & 19.20 & 31.50 \\
\hline & СТЕРН & 25 & $24.09 \pm 2.05$ & 19.20 & 27.50 \\
\hline & Normal & 50 & $18.89 \pm 2.81$ & 12.90 & 25.10 \\
\hline \multirow{4}{*}{ Left Main Pulmonary Artery Diameter (mm) } & $\mathrm{PE}$ & 55 & $21.05 \pm 3.37$ & 15.20 & 30.00 \\
\hline & $\mathrm{PH}$ & 20 & $23.82 \pm 3.54$ & 18.90 & 33.70 \\
\hline & СТЕРН & 25 & 24.122.19 & 20.00 & 29.10 \\
\hline & Normal & 50 & $19.56 \pm 3.02$ & 14.10 & 26.70 \\
\hline \multirow{4}{*}{ Right Distal Pulmonary Artery Diameter (mm) } & $\mathrm{PE}$ & 55 & $3.21 \pm 0.40$ & 2.50 & 4.50 \\
\hline & $\mathrm{PH}$ & 20 & $3.34 \pm 0.30$ & 2.70 & 3.70 \\
\hline & СТЕРН & 25 & $3.43 \pm 0.39$ & 2.50 & 4.10 \\
\hline & Normal & 50 & $3.22 \pm 0.32$ & 2.50 & 4.10 \\
\hline \multirow{4}{*}{ Left Distal Pulmonary Artery Diameter (mm) } & $\mathrm{PE}$ & 55 & $3.23 \pm 0.38$ & 2.60 & 4.80 \\
\hline & $\mathrm{PH}$ & 20 & $3.31 \pm 0.35$ & 2.50 & 3.90 \\
\hline & СТЕРН & 25 & $3.42 \pm 0.38$ & 2.40 & 4.20 \\
\hline & Normal & 50 & $3.15 \pm 0.29$ & 2.40 & 3.80 \\
\hline
\end{tabular}


of the studied cases, these were presented in Table 4. Our study measured the right atrium and right ventricle diameters, they were of largest values in patients affected with PH and CTEPH; mean diameter $60.31 \pm 11.49$, $57.42 \pm 9.19$ and $51.41 \pm 6.34,51.31 \pm 5.94$ in respectively. The inter-ventricular septum width was also changed with the presence of the diseases; however the myocardium thickening changes does not differ with different presentations of diseases. Changes are compensatory mechanisms that allow the right ventricle to maintain cardiac output [47] [48]. These scientific facts justify our findings.

Tables 5-7 presented the significant difference between the variables which have been evaluated in patients with and without PE, PH and CTEPH. Right atrium, right ventricle, pulmonary trunk, right main pulmonary artery, left main pulmonary artery diameters measurements were changed significantly in both patients with PE and PH when compared with the norms. While in CTEPH all of the anatomical structures which have been evaluated including (heart segments, pulmonary tree) were differed significantly at $\mathrm{p} \leq 0.05$. Numerous studies have investigated the correlation between CT measurements of the pulmonary artery and the presence of PH. Overall,

Table 5. Independent samples test for equality of means between the measured variables in patients with and without PE.

\begin{tabular}{ccc}
\hline Independent Samples Test ${ }^{*}$ & & \\
\hline Patients with and without PE & \multicolumn{1}{c}{ t-test for Equality of Means } \\
\hline Right Atrium Diameter (mm) & t & Sig. (2-tailed) \\
Right Ventricle Diameter (mm) & 2.071 & 0.041 \\
Inter-Ventricular Septum Width (mm) & 3.692 & 0.000 \\
Myocardium thickening (mm) & 1.281 & 0.203 \\
Pulmonary Trunk Diameter (mm) & 1.233 & 0.220 \\
Right Main Pulmonary Artery Diameter (mm) & 4.100 & 0.000 \\
Left Main Pulmonary Artery Diameter (mm) & 2.982 & 0.004 \\
Right Distal Pulmonary Artery Diameter (mm) & 2.370 & 0.020 \\
Left Distal Pulmonary Artery Diameter (mm) & -0.101 & 0.920 \\
\hline
\end{tabular}

${ }^{*}$ Correlation is significant at $p \leq 0.05$.

Table 6. Independent samples test for equality of means between the measured variables in patients with and without PH.

\begin{tabular}{ccc}
\hline Independent Samples Test & & \\
Patients with and without PH & \multicolumn{1}{c}{ t-test for Equality of Means } \\
\hline Right Atrium Diameter (mm) & t & Sig. (2-tailed) \\
Right Ventricle Diameter (mm) & 6.418 & 0.000 \\
Inter-Ventricular Septum Width (mm) & 7.389 & 0.000 \\
Myocardium Thickening (mm) & -0.480 & 0.633 \\
Pulmonary Trunk Diameter (mm) & 0.025 & 0.980 \\
Right Main Pulmonary Artery Diameter (mm) & 7.624 & 0.000 \\
Left Main Pulmonary Artery Diameter (mm) & 5.092 & 0.000 \\
Right Distal Pulmonary Artery Diameter (mm) & 5.059 & 0.000 \\
Left Distal Pulmonary Artery Diameter (mm) & 1.482 & 0.143 \\
\hline
\end{tabular}

\footnotetext{
${ }^{*}$ Correlation is significant at $p \leq 0.05$.
} 
Table 7. Independent samples test for equality of means between the measured pulmonary tree in patients with and without CTEPH.

\begin{tabular}{|c|c|c|}
\hline \multicolumn{3}{|c|}{ Independent Samples Test ${ }^{*}$} \\
\hline \multirow{2}{*}{ Patients with and without CTEPH } & \multicolumn{2}{|c|}{ t-test for Equality of Means } \\
\hline & $\mathrm{t}$ & Sig. (2-tailed) \\
\hline Right Atrium Diameter (mm) & 6.013 & 0.000 \\
\hline Right Ventricle Diameter (mm) & 7.956 & 0.000 \\
\hline Inter-Ventricular Septum Width (mm) & 3.208 & 0.002 \\
\hline Myocardium Thickening (mm) & 2.120 & 0.037 \\
\hline Pulmonary Trunk Diameter (mm) & 10.323 & 0.000 \\
\hline Right Main Pulmonary Artery Diameter (mm) & 8.198 & 0.000 \\
\hline Left Main Pulmonary Artery Diameter (mm) & 6.694 & 0.000 \\
\hline Right Distal Pulmonary Artery Diameter (mm) & 2.529 & 0.014 \\
\hline Left Distal Pulmonary Artery Diameter (mm) & 3.453 & 0.001 \\
\hline
\end{tabular}

"Correlation is significant at $p \leq 0.05$.

the measurement of the main pulmonary artery size by using CT shows a moderate to strong correlation with PH [40]. However, Moore et al. reported no correlation between main pulmonary artery size in patients with PH and chronic thromboembolic pulmonary hypertension (CTEPH) [49]. The presence of significant parenchymal lung disease, which can distort the great vessel anatomy, also appears to affect the correlation between $\mathrm{PH}$ and pulmonary artery size [27].

The significant difference that was noticed in the measurements done in both normal patients and patients with CTEPH give the evaluation of the pulmonary artery and its branches an important approach; because the pulmonary artery size was associated with unexpected death [50].

In summary, although CT measurements of pulmonary artery dimensions have shown a correlation with the presence of PH, PE and CTEPH; the strength of the correlation is highly variable. Future studies could focus on specific disease and changes in the pulmonary artery size as a marker of prognosis, disease activity, and treatment response, rather than as an isolated measure. CT measures of pulmonary artery size are simple and can suggest a possible reason for dyspnea but it should be interpreted cautiously and not be used solely in either screening or guiding management in the patients with suspected PH or patients with PE and CTEPH. Our results suggest that right ventricle, right atrium dilation on CTPA may represent an additional marker of severe PE, PH and CTEPH and such patients should be considered as being at increased risk of adverse outcome. The current findings were reliable with Aran Singanayagam et al. (2010) scientific findings [51].

Limitations: Firstly, the presence of artifacts during breath holds technique because it is difficult to be done regarding the patients complain as shortness in breathing and chest pain. Secondly, relying on simple measurement might only provide limited information. However, our study in different patients' diseases shows the value of uncomplicated measurements in axial CT images that are frequently performed as a first line examination. Third drawback was that our analysis involved relatively few patients and small sample size. Finally, using only the clinical features in diagnosing of PH without using another imaging or laboratory method; however a large set of data on various CT changes in different diseases were characterized.

\section{Conclusion}

Knowledge of the radiological features of PH, PE and CTEPH is mandatory for accurately diagnosing the condition and possibly will improve the outcome. Awareness of the various disease entities associated with $\mathrm{PH}$ and knowledge of the entire spectrum of their CT imaging features are essential. In the current study the pulmonary artery tree, cardiac segments and associated lung parenchyma findings have been evaluated and the added value of CT in prediction of estimating PH comparing with the normal control group was analyzed. It was found that 
CTA plays an important role in the diagnostic evaluation of patients with PH. CT imaging is acceptably used in establishing the diagnosis, defining the cause, quantifying heart segments and parenchyma changes in order to assess the feasibility of surgery, therapeutic planning and monitoring patients with $\mathrm{PH}$.

\section{References}

[1] McLaughlin, V.V. and McGoon, M.D. (2006) Pulmonary Arterial Hypertension. Circulation, 114, 1417-1431. http://dx.doi.org/10.1161/CIRCULATIONAHA.104.503540

[2] Mehta, S., Helmersen, D., Provencher, S., et al. (2010) Diagnostic Evaluation and Management of Chronic Thromboembolic Pulmonary Hypertension: A Clinical Practice Guideline. Canadian Respiratory Journal, 17, 301-334. http://dx.doi.org/10.1155/2010/704258

[3] Galie, N., Hoeper, M.M., Humbert, M., et al. (2009) Guidelines for the Diagnosis and Treatment of Pulmonary Hypertension: The Task Force for the Diagnosis and Treatment of Pulmonary Hypertension of the European Society of Cardiology (ESC) and the European Respiratory Society (ERS), Endorsed by the International Society of Heart and Lung Transplantation (ISHLT). European Heart Journal, 30, 2493-2537. http://dx.doi.org/10.1093/eurheartj/ehp297

[4] Reaside, D. and Peacock, A. (1997) Making Measurements in the Pulmonary Circulation: When and How? Thorax, 52, 9-11. http://dx.doi.org/10.1136/thx.52.1.9

[5] Kereiakes, D.J., Herfkens, R.J., Brundage, B.H., Gamsu, G. and Lipton, M.J. (1983) Computerized Tomography in Chronic Thromboembolic Pulmonary Hypertension. American Heart Journal, 106, 1432-1436. http://dx.doi.org/10.1016/0002-8703(83)90058-3

[6] Tardivon, A.A., Musset, D., Maitre, S., et al. (1993) Role of CT in Chronic Pulmonary Embolism: Comparison with Pulmonary Angiography. Journal of Computer Assisted Tomography, 17, 345-351. http://dx.doi.org/10.1097/00004728-199305000-00001

[7] Falaschi, F., Palla, A., Formichi, B., et al. (1992) CT Evaluation of Chronic Thromboembolic Pulmonary Hypertension. Journal of Computer Assisted Tomography, 16, 897-903. http://dx.doi.org/10.1097/00004728-199211000-00013

[8] Schwickert, H.C., Schweden, F., Schildt, H.H., et al. (1994) Pulmonary Arteries and Lung Parenchyma in Chronic Pulmonary Embolism: Preoperative and Postoperative CT Findings. Radiology, 191, 351-357. http://dx.doi.org/10.1148/radiology.191.2.8153305

[9] Bergin, C.J., Sirlin, C.B., Hauschildt, J.P., et al. (1997) Chronic Thromboembolism: Diagnosis with Helical CT and MR Imaging with Angiographic and Surgical Correlation. Radiology, 204, 695-702. http://dx.doi.org/10.1148/radiology.204.3.9280245

[10] Remy-Jardin, M., Louvegny, S., Remy, J., et al. (1997) Acute Central Thromboembolic Disease: Post Therapeutic Follow-Up with Spiral CT Angiography. Radiology, 203, 173-189. http://dx.doi.org/10.1148/radiology.203.1.9122389

[11] Bergin, C.J., Hauschildt, H.P., Brown, M.A., et al. (1999) Identifying the Cause of Unilateral Hypoperfusion in Patients Suspected to Have Chronic Pulmonary Thromboembolism: Diagnostic Accuracy of Helical and Conventional Angiography. Radiology, 213, 743-749. http://dx.doi.org/10.1148/radiology.213.3.r99dc40743

[12] Pengo, V., Lensing, A.W., Prins, M.H., et al. (2004) Incidence of Chronic Thromboembolic Pulmonary Hypertension after Pulmonary Embolism. New England Journal of Medicine, 350, 2257-2264. http://dx.doi.org/10.1056/NEJMoa032274

[13] Tapson, V.F. and Humbert, M. (2006) Incidence and Prevalence of Chronic Thromboembolic Pulmonary Hypertension: From Acute to Chronic Pulmonary Embolism. Proceedings of the American Thoracic Society, 3, 564-567. http://dx.doi.org/10.1513/pats.200605-112LR

[14] Castañer, E., Gallardo, X., Ballesteros, E., Andreu, M., Pallardó, Y., Mata, J.M. and Riera, L. (2009) MDCT Diagnosis of Chronic Pulmonary Thromboembolism. RadioGraphics, 29, 31-53. http://dx.doi.org/10.1148/rg.291085061

[15] Fedullo, P.F., Auger, W.R., Kerr, K.M. and Rubin, L.J. (2001) Chronic Thrombo Embolic Pulmonary Hypertension. New England Journal of Medicine, 345, 1465-1472. http://dx.doi.org/10.1056/NEJMra010902

[16] Moser, K.M., Auger, W.R., Fedullo, P.F. and Jamieson, S.W. (1992) Chronic Thrombo Embolic Pulmonary Hypertension: Clinical Picture and Surgical Treatment. European Respiratory Journal, 5, 334-342.

[17] Rich, S., Levitsky, S. and Brundage, B.H. (1988) Pulmonary Hypertension from Chronic Pulmonary Thrombo Embolism. Annals of Internal Medicine, 108, 425-434. http://dx.doi.org/10.7326/0003-4819-108-3-425

[18] Frazier, A.A., Galvin, J.R., Franks, T.J. and Rosado-de-Christenson, M.L. (2000) Pulmonary Vasculature: Hypertension and Infarction. RadioGraphics, 20, 491-524. http://dx.doi.org/10.1148/radiographics.20.2.g00mc17491

[19] Barst, R.J., McGoon, M., Torbicki, A., et al. (2004) Diagnosis and Differential Assessment of Pulmonary Arterial Hypertension. Journal of the American College of Cardiology, 43, 40S-47S. http://dx.doi.org/10.1016/j.jacc.2004.02.032 
[20] Trow, T.K. and McArdle, J.R. (2007) Diagnosis of Pulmonary Arterial Hypertension. Clinics in Chest Medicine, 28, 59-73. http://dx.doi.org/10.1016/j.ccm.2006.11.001

[21] Benza, R., Biederman, R., Murali, S. and Gupta, H. (2008) Role of Cardiac Magnetic Resonance Imaging in the Management of Patients with Pulmonary Arterial Hypertension. Journal of the American College of Cardiology, 52, 16831692. http://dx.doi.org/10.1016/j.jacc.2008.08.033

[22] Biederman, R.W. (2009) Cardiovascular Magnetic Resonance Imaging as Applied to Patients with Pulmonary Arterial Hypertension. International Journal of Clinical Practice, 63, 20-35. http://dx.doi.org/10.1111/j.1742-1241.2009.02109.x

[23] Peña, E., Dennie, C., Veinot, J. and Muñiz, S.H. (2012) Pulmonary Hypertension: How the Radiologist Can Help. RadioGraphics, 32, 9-32.

[24] Bonderman, D., Jakowitsch, J., Adlbrecht, C., et al. (2005) Medical Conditions Increasing the Risk of Chronic Thromboembolic Pulmonary Hypertension. Thrombosis and Haemostasis, 93, 512-516.

[25] Dartevelle, P., Fadel, E., Mussot, S., et al. (2004) Chronic Thrombo Embolic Pulmonary Hypertension. European Respiratory Journal, 23, 637-648. http://dx.doi.org/10.1183/09031936.04.00079704

[26] McLaughlin, V.V., Presberg, K.W., Doyle, R.L., et al. (2004) Prognosis of Pulmonary Arterial Hypertension: ACCP Evidence-Based Clinical Practice Guidelines. Chest, 126, 78S-92S. http://dx.doi.org/10.1378/chest.126.1_suppl.78S

[27] Tan, R.T., Kuzo, R., Goodman, L.R., Siegel, R., Haasler, G.B. and Presberg, K.W. (1998) Utility of CT Scan Evaluation for Predicting Pulmonary Hypertension in Patients with Parenchymal Lung Disease. Medical College of Wisconsin Lung Transplant Group. Chest, 113, 1250-1256. http://dx.doi.org/10.1378/chest.113.5.1250

[28] Barbosa Jr., E.J.M., Gupta, N.K., Torigian, D.A. and Gefter, W.B. (2012) Current Role of Imaging in the Diagnosis and Management of Pulmonary Hypertension. American Journal of Roentgenology, 198, 1320-1331.

[29] Horton, M.R. and Tuder, R.M. (2004) Primary Pulmonary Arterial Hypertension Presenting as Diffuse Micronodules on CT. Critical Reviews in Computed Tomography, 45, 335-341. http://dx.doi.org/10.3109/10408370490888442

[30] Resten, A., Maître, S., Humbert, M., et al. (2002) Pulmonary Arterial Hypertension: Thin-Section CT Predictors of Epoprostenol Therapy Failure. Radiology, 222, 782-788. http://dx.doi.org/10.1148/radiol.2223010668

[31] Hansell, D.M. (2002) Small-Vessel Diseases of the Lung: CT-Pathologic Correlates. Radiology, 225, 639-653. http://dx.doi.org/10.1148/radiol.2253011490

[32] Chitwood Jr., W.R., Lyerly, H.K. and Sabiston Jr., D.C. (1985) Surgical Management of Chronic Pulmonary Embolism. Annals of Surgery, 201, 11-26.

[33] Arakawa, H., Stern, E.J., Nakamoto, T., Fujioka, M., Kaneko, N. and Harasawa, H. (2003) Chronic Pulmonary Thromboembolism. Air Trapping on Computed Tomography and Correlation with Pulmonary Function Tests. Journal of Computer Assisted Tomography, 27, 735-742. http://dx.doi.org/10.1097/00004728-200309000-00010

[34] Nauser, T.D. and Stites, S.W. (2001) Diagnosis and Treatment of Pulmonary Hypertension. American Family Physician, 63, 1789-1798.

[35] Bristow, M.R., Zisman, L.S., Lowes, B.D., et al. (1998) The Pressure-Overloaded Right Ventricle in Pulmonary Hypertension. Chest, 114, 101S-106S. http://dx.doi.org/10.1378/chest.114.1_Supplement.101S

[36] Schmidt, H.C., Kauczor, H.U., Schild, H.H., et al. (1996) Pulmonary Hypertension in Patients with Chronic Pulmonary Thromboembolism: Chest Radiograph and CT Evaluation before and after Surgery. European Radiology, 6, 817-825. http://dx.doi.org/10.1007/BF00240678

[37] Edwards, P.D., Bull, R.K. and Coulden, R. (1998) CT Measurement of Main Pulmonary Artery Diameter. The British Journal of Radiology, 71, 1018-1020. http://dx.doi.org/10.1259/bjr.71.850.10211060

[38] Karazincir, S., Balci, A., Seyfeli, E., Akoglu, S., Babayigit, C., Akgul, F., Yalcin, F. and Egilmez, E. (2008) CT Assessment of Main Pulmonary Artery Diameter. Diagnostic and Interventional Radiology, 14, 72-74.

[39] Kuriyama, K., Gamsu, G., Stern, R.G., Cann, C.E., Herfkens, R.J. and Brundage, B.H. (1984) CT-Determined Pulmonary Artery Diameters in Predicting Pulmonary Hypertension. Investigative Radiology, 19, 16-22. http://dx.doi.org/10.1097/00004424-198401000-00005

[40] Ussavarungsi, K., Whitlock, J.P., Lundy, T.A., Carabenciov, I.D., Burger, C.D. and Lee, A.S. (2014) The Significance of Pulmonary Artery Size in Pulmonary Hypertension. Diseases, 2, 243-259.

[41] Devaraj, A. and Hansell, D.M. (2009) Computed Tomography Signs of Pulmonary Hypertension: Old and New Observations. Clinical Radiology, 64, 751-760. http://dx.doi.org/10.1016/j.crad.2008.12.005

[42] King, M.A., Ysrael, M. and Bergin, C.J. (1998) Chronic Thromboembolic Pulmonary Hypertension: CT Findings. American Journal of Roentgenology, 170, 955-960. http://dx.doi.org/10.2214/ajr.170.4.9530043

[43] Reid, J.H. and Murchison, J.T. (1998) Acute Right Ventricular Dilatation: A New Helical CT Sign of Massive Pulmonary Embolism. Clinical Radiology, 53, 694-698. http://dx.doi.org/10.1016/S0009-9260(98)80297-3 
[44] Van der Meer, R.W., Pattynama, P.M., van Strijen, M.J., et al. (2005) Right Ventricular Dysfunction and Pulmonary Obstruction Index at Helical CT: Prediction of Clinical Outcome during 3-Month Follow-Up in Patients with Acute Pulmonary Embolism. Radiology, 235, 798-803. http://dx.doi.org/10.1148/radiol.2353040593

[45] Groves, A.M., Win, T., Charman, S.C., Wisbey, C., Pepke-Zaba, J. and Coulden, R.A. (2004) Semi-Quantitative Assessment of Tricuspid Regurgitation on Contrast-Enhanced Multidetector CT. Clinical Radiology, 59, 715-719. http://dx.doi.org/10.1016/j.crad.2004.02.007

[46] Baque-Juston, M.C., Wells, A.U. and Hansell, D.M. (1999) Pericardial Thickening or Effusion in Patients with Pulmonary Artery Hypertension: A CT Study. American Journal of Roentgenology, 172, 361-364. http://dx.doi.org/10.2214/ajr.172.2.9930782

[47] Dell’Italia, L.J. and Santamore, W.P. (1998) Can Indices of Left Ventricular Function Be Applied to the Right Ventricle? Progress in Cardiovascular Diseases, 40, 309-324. http://dx.doi.org/10.1016/S0033-0620(98)80050-9

[48] McGoon, M., Gutterman, D., Steen, V., et al. (2004) Screening, Early Detection, and Diagnosis of Pulmonary Arterial Hypertension: ACCP Evidence-Based Clinical Practice Guidelines. Chest, 126, 14-34S. http://dx.doi.org/10.1378/chest.126.1_suppl.14S

[49] Moore, N.R., Scott, J.P., Flower, C.D. and Higenbottam, T.W. (1988) The Relationship between Pulmonary Artery Pressure and Pulmonary Artery Diameter in Pulmonary Hypertension. Clinical Radiology, 39, 486-489. http://dx.doi.org/10.1016/S0009-9260(88)80205-8

[50] Zylkowska, J., Kurzyna, M., Florczyk, M., Burakowska, B., Grzegorczyk, F., Burakowski, J., Wieteska, M., Oniszh, K., Biederman, A., Wawrzynska, L., et al. (2012) Pulmonary Artery Dilatation Correlates with the Risk of Unexpected Death in Chronic Arterial or Thromboembolic Pulmonary Hypertension. Chest, 142, 1406-1416. http://dx.doi.org/10.1378/chest.11-2794

[51] Singanayagam, A., Chalmers, J.D., Scally, C., Akram, A.R., Al-Khairalla, M.Z., Leitch, L., Hill, L.E. and Hill, A.T. (2010) Right Ventricular Dilation CT Pulmonary Angiogram Independently Predicts Mortality in Pulmonary Embolism. Respiratory Medicine, 104, 1057-1062.

\section{Submit or recommend next manuscript to SCIRP and we will provide best service for you:}

Accepting pre-submission inquiries through Email, Facebook, LinkedIn, Twitter, etc.

A wide selection of journals (inclusive of 9 subjects, more than 200 journals)

Providing 24-hour high-quality service

User-friendly online submission system

Fair and swift peer-review system

Efficient typesetting and proofreading procedure

Display of the result of downloads and visits, as well as the number of cited articles

Maximum dissemination of your research work

Submit your manuscript at: http://papersubmission.scirp.org/ 